\title{
Developing BACE-1 inhibitors for FXS
}

\section{Cara J. Westmark ${ }^{1}$, Elizabeth M. Berry-Kravis ${ }^{2}$, Chrysanthy Ikonomidou ${ }^{1}$, Jerry C. P. Yin ${ }^{3}$ and Luigi Puglielli ${ }^{4}$}

\author{
${ }^{1}$ Department of Neurology, University of Wisconsin, Madison, WI, USA \\ ${ }^{2}$ Department of Pediatrics, Biochemistry and Neurological Sciences, Rush University Medical Center, Chicago, IL, USA \\ ${ }^{3}$ Department of Genetics, University of Wisconsin, Madison, WI, USA \\ ${ }^{4}$ Department of Medicine, University of Wisconsin, Madison, WI, USA
}

\section{Edited by:}

Rena Li, Roskamp Institute, USA

\section{Reviewed by:}

Zhongcong Xie, Massachusetts General Hospital and Harvard Medical School, USA

Xin Cheng, Huashan Hospital Fudan

University, China

\section{*Correspondence:}

Cara J. Westmark, Department of

Neurology, University of Wisconsin,

Medical Sciences Center, 1300

University Avenue, Madison, WI

53706, USA.

e-mail:westmark@facstaff.wisc.edu
Fragile $X$ syndrome (FXS) is a debilitating genetic disorder with no cure and few therapeutic options. Excessive signaling through metabotropic glutamate receptor 5 in FXS leads to increased translation of numerous synaptic proteins and exaggerated long-term depression. Two of the overexpressed proteins are amyloid-beta protein precursor (APP) and its metabolite amyloid-beta, which have been well-studied in Alzheimer's disease (AD). Here we discus the possibility that pharmaceuticals under study for the modulation of these proteins in $A D$ might be viable therapeutic strategies for FXS. Specifically, a recently identified acetyltransferase inhibitor that reduces the levels and activity of $\beta$-site APP cleaving enzyme (BACE-1) has strong potential to attenuate BACE-1 activity and maintain homeostatic levels APP catabolites in FXS.

Keywords: fragile X syndrome, BACE-1, Alzheimer's disease, amyloid-beta, mGluR ${ }_{5}$

\section{INTRODUCTION}

Fragile X syndrome (FXS) is the most common form of inherited intellectual disability and the leading known genetic cause of autism (Wang et al., 2010). Clinical features include moderate to severe intellectual disability, autistic-like behavior, anxiety, seizures, and macroorchidism (Hagerman et al., 2009). Neuroanatomical features include an overabundance of long, thin tortuous postsynaptic spines (Beckel-Mitchener and Greenough, 2004). In the majority of cases, FXS is caused by a trinucleotide repeat expansion in the promoter region of the fragile $\mathrm{X}$ mental retardation 1 (FMR1) gene, which leads to promoter methylation and lack of translation of fragile $\mathrm{X}$ mental retardation protein (FMRP). FMRP is an mRNA binding protein that regulates dendritic protein synthesis. Research spanning the past two decades has identified metabotropic glutamate receptor $5\left(\mathrm{mGluR}_{5}\right)$ as a key member of a group of Gq-linked receptors that activate dendritic translation through a signaling cascade upstream of FMRP. There has been an intense effort to identify the intermediate signaling molecules in the cascade as well as downstream FMRP mRNA targets (Bhakar et al., 2012). In aggregate, over 500 mRNA ligands have been identified, many with potential to influence synaptic structure and plasticity, but only about a dozen have been validated as evidenced by association with FMRP, dendritic localization, or synaptic synthesis, and regulation by group 1 mGluR (Bassell and Warren, 2008). We validated App mRNA as a synaptic target that is translationally regulated by FMRP and mGluR $_{5}$ (Westmark and Malter, 2007). App mRNA codes for a transmembrane protein amyloid-beta protein precursor (APP), which is processed by $\beta$ and $\gamma$-secretases to generate amyloid-beta $(A \beta)$, the predominant protein found in the senile plaques characteristic of Alzheimer's disease (AD) and Down syndrome. Fmr1 ${ }^{K O}$ mice, which lack the translational repressor FMRP, exhibit elevated levels of brain APP and $A \beta$, and the brains of FXS patients also appear to have elevated $A \beta$ (Westmark et al., 2011b). Importantly, downregulation of APP and consequent reduction of $A \beta$ can rescue many phenotypic abnormalities of $\mathrm{Fmrl}^{\mathrm{KO}}$ mice (Westmark et al., 2011b). Thus, it is our opinion that therapies directed at normalizing APP and $A \beta$ levels will benefit FXS. Our opinion is relevant and timely as $\beta$-site APP cleaving enzyme (BACE-1) inhibitors are entering clinical trials for the treatment of mild cognitive impairment and AD. Positive results could be rapidly extrapolated to the treatment of FXS, which is considered an orphan disease from the standpoint of treatment development. Herein, we provide a framework for preclinical studies validating APP and A $\beta$ pathophysiology and BACE-1 inhibitor efficacy in animal models of FXS.

\section{THE mGIUR THEORY OF FXS}

"The mGluR Theory of Fragile X" proposed by Bear et al. (2004) proposes that overactive signaling by group $1 \mathrm{mGluRs}$ ( $\mathrm{mGluR}_{1}$ and $\mathrm{mGluR}_{5}$ ) contributes to many of the psychiatric and neurological symptoms of FXS. The theory contends that FMRP binds to synaptic mRNAs and represses their translation. Upon mGluR 5 activation, FMRP is inactivated or dislodged from target mRNAs, and rapid dendritic synthesis of new proteins leads to long-term depression (LTD) at locally active synapses. In the absence of FMRP, GGluR $_{5}$-mediated translation is constitutive and unregulated. There has been an intense effort by the FXS community to validate the central role of $\mathrm{mGluR}_{5}$ in FXS. A $50 \%$ genetic reduction of mGluR 5 levels in $\mathrm{Fmrl}^{\mathrm{KO}}$ mice rescues ocular dominance plasticity, the density of dendritic spines, basal protein synthesis, inhibitory avoidance extinction, audiogenic seizures, and macroorchidism (Dolen etal., 2007); and pharmacological treatment with mGluR $_{5}$ antagonists rescues FXS phenotypes in mouse (Mus musculus), fly (Drosophila melanogaster), and 
zebrafish (Danio rerio) disease models (McBride et al., 2005; Yan et al., 2005; Tucker et al., 2006; de Vrij et al., 2008; Michalon et al., 2012). In addition, numerous signaling molecules, convergent signaling pathways and other membrane receptors have been identified that contribute to the abnormal synaptic plasticity observed in FXS. Other interacting, and in some cases overlapping, theories have emerged. "The cAMP Theory of FXS" suggests that alterations in cAMP production contribute to FXS neuropathology (Kelley et al., 2007). The "The $\mathrm{GABA}_{\mathrm{A}} \mathrm{R}$ Hypothesis" postulates that $\mathrm{GABA}_{\mathrm{A}} \mathrm{R}$ is a potential therapeutic target because GABAergic agonists rescue behavioral symptoms of FXS (Heulens et al., 2012). Key FMRP ligands coding for "LTD proteins" have been identified and are potential therapeutic targets (Luscher and Huber, 2010).

\section{APP AT THE FXS SYNAPSE}

We identified $A p p$ mRNA as a synaptic target for $\mathrm{mGluR}_{5} / \mathrm{FMRP}$ regulation (Westmark and Malter, 2007). FMRP binds to a guanine-rich region in the coding region of APP mRNA and inhibits translation (Westmark and Malter, 2007; Lee etal., 2010). Stimulation with the group 1 mGluR agonist (S)-3,5dihydroxyphenylglycine (DHPG) releases FMRP from the App message resulting in increased APP production. In $\mathrm{Fmrl}^{\mathrm{KO}}$ synaptoneurosomes and primary neurons, which lack FMRP, basal APP levels are elevated (Westmark and Malter, 2007; Liao et al., 2008) and do not change in response to DHPG. Consistent with these findings, $\mathrm{A} \beta$ levels are elevated in the brain of $F m r 1^{K O}$ mice, and several FXS phenotypes including mGluR-LTD can be rescued by genetically reducing APP and A $\beta$ levels $\left(F m r 1^{K O} / A P p^{H E T}\right.$ mice; Westmark and Malter, 2007; Westmark et al., 2011b).

Amyloid-beta protein precursor functions in synapse and dendritic spine formation, synaptic transmission, and learning and memory (Hoe et al., 2012). Expression is developmentally regulated with maximal levels during synaptogenesis and subsequent decline when mature connections are completed. Pathological examination of brains from FXS patients shows an increased density of long and tortuous dendritic spines. Similarly, $F m r 1^{K O}$ mice exhibit elevated spine protrusion length compared to wild type (WT) littermates. During the first two postnatal weeks, immature filopodia are replaced by mushroom-shaped spines in WT mice whereas $F m r 1^{K O}$ exhibit a developmental delay in the transition from immature to mature spines (Cruz-Martin et al., 2010). Likewise, $A \beta$ is strongly implicated in impaired synaptic function (Koffie et al., 2011). Soluble A $\beta$ oligomers facilitate LTD, similar to the enhancement of LTD that occurs in the hippocampus of $\mathrm{Fmrl}^{\mathrm{KO}}$ mice (Huber et al., 2002), and inhibit long-term potentiation (LTP). A $\beta$ is associated with increased hyperexcitability and seizure activity in AD mice (Palop et al., 2007). Interstitial fluid levels of $A \beta$ vary diurnally in both $\mathrm{WT}$ and $\mathrm{AD}$ mouse models with increased levels associated with wakefulness (Kang et al., 2009). Thus, we predict that the dysregulated expression of APP and its catabolites during FXS development contributes to aberrant synapse formation leading to seizures and behavioral, cognitive and sleep deficits.

A comparison of the AD and FXS literature demonstrates that many of the identified receptor and signaling molecules with established roles in FXS are regulated by APP and/or A $\beta$ (Figure 1). These findings support the contention that APP and
$\mathrm{A} \beta$ are key LTD proteins that contribute to FXS pathology, and that therapeutics currently under study for the modulation of APP processing and $\mathrm{A} \beta$ levels in $\mathrm{AD}$ may be applicable to FXS. A caveat to this opinion is that there is no evidence of increased AD pathology in older FXS individuals. Regardless if $A \beta$ forms insoluble plaques in FXS, increasing evidence suggests that soluble, oligomeric forms of $A \beta$ are the pathogenic form of the peptide (Ferreira and Klein, 2011).

\section{MAINTAINING SYNAPTIC HOMEOSTASIS IN FXS}

Deviations in either direction from the optimal level of synaptic proteins can adversely affect plasticity (Kelleher and Bear, 2008). Synaptic deficits in Tsc2 and Fmr1 mutant mice are corrected by treatments that modulate $\mathrm{mGluR}_{5}$ in opposite directions and disappear in mice that carry both mutations (Auerbach et al., 2011). Similarly, "too much" or "too little" APP and A $\beta$ in $F m r 1^{K O}$ mice exacerbates audiogenic seizures (Westmark et al., 2010, 2013). These data support the requirement for maintenance of homeostatic levels of key synaptic proteins in the treatment of FXS and suggest that therapeutic dosages need to be tightly regulated. In fact, it is likely that a cocktail of low dosage drugs will be required to maintain synaptic homeostasis. The results of early-phase clinical trials with targeted FXS therapeutics have been reviewed (BerryKravis et al., 2011; Gross et al., 2012). Surprisingly, several of these drugs may be effective in FXS due to off-site activities that modulate APP, $A \beta$, and/or BACE-1. Table 1 lists the drugs in clinical trials for FXS, their known activities and their expected effects on APP, $\mathrm{A} \beta$, and BACE-1. Fenobam, lithium, memantine, and minocycline modulate APP, $\mathrm{A} \beta$, and/or BACE-1. The other listed drugs are predicted to modulate these proteins based on their mechanism of action [GABA agonist (Sun et al., 2012), mGluR $_{5}$ antagonist (Westmark and Malter, 2007), glycogen synthase kinase-3 (GSK3) inhibitor (Yu et al., 2012), neurosteroid (Chen et al., 2011), statin (Kojro et al., 2001), serotonin reuptake inhibitor (Cochet et al., 2013), or antioxidants (Heo et al., 2013)].

Amyloid-beta protein precursor and $A \beta$ are implicated in both negative and positive feedback loops predicted to affect synaptic homeostasis. Kamenetz et al. (2003) determined that neuronal activity modulates the generation and secretion of $A \beta$ peptides from hippocampal neurons that overexpress APP. $\mathrm{A} \beta$ in turn selectively depresses excitatory synaptic transmission through $\mathrm{N}$-methyl D-aspartate receptor (NMDAR) thus completing a negative feedback loop. Renner etal. (2010) showed that $A \beta$ oligomers cause dynamic redistribution of $\mathrm{mGluR}_{5}$ to synapses and thus facilitate increased $\mathrm{mGluR}_{5}$ signaling. We demonstrated that A $\beta$ induces dendritic APP translation in primary cultured neurons through an $\mathrm{mGluR}_{5}$-dependent pathway (Westmark et al., 2011b). Together these studies suggest a positive feedback loop whereby $A \beta$ oligomers facilitate $\mathrm{mGluR}_{5}$ signaling leading to increased dendritic APP translation, which provides more target for amyloidogenic processing and the generation of additional $A \beta$ (Ferreira and Klein, 2011; Westmark, 2013).

\section{SECRETASES MODULATE APP PROCESSING}

Anti-A $\beta$ therapies and secretase inhibitors are leading strategies for reducing $A \beta$ in $A D$. $A \beta$ immunotherapy has proved very effective 


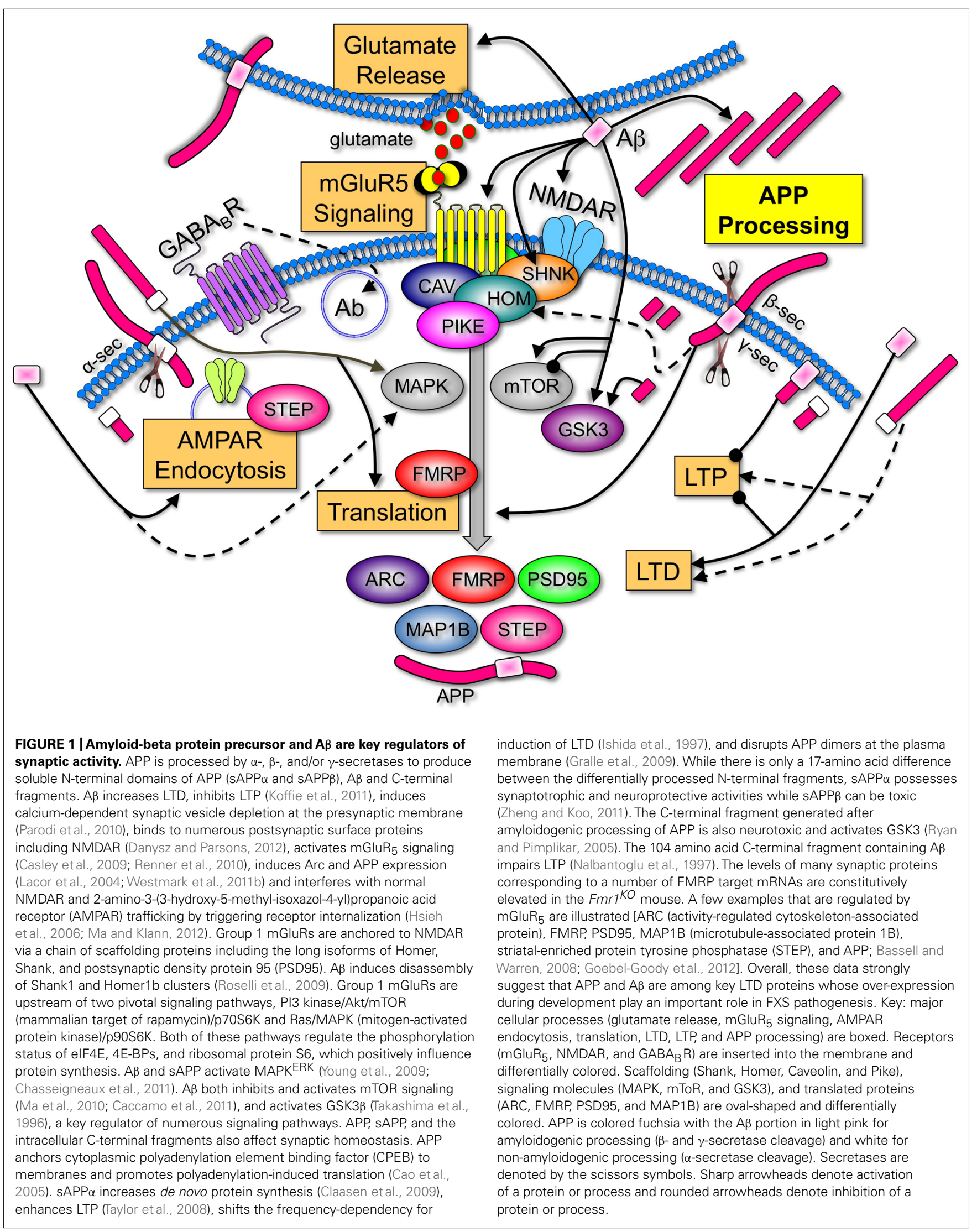


in reducing soluble $A \beta$, amyloid plaque and soluble tau as well as associated cognitive decline in $\mathrm{AD}$ mouse models; however, there are safety questions (Morgan, 2011). An alternative approach is modulation of secretase activity. $\beta$ - and $\gamma$-secretase inhibitors are currently in the preclinical stage of investigation for $\mathrm{AD}$ and could provide a means to reduce amyloidogenic processing in FXS. BACE-1 is a type I transmembrane aspartyl protease that functions as the rate limiting step in the generation of $A \beta$. A BACE-1 inhibitor significantly reduces plasma and brain $A \beta$ in AD model mice (Ghosh et al., 2008, 2012; Chang et al., 2011). The potential advantage of BACE-1 inhibitors over $\mathrm{mGluR}_{5}$ antagonists and anti-A $\beta$ immunotherapy is that the latter therapies can reduce APP and soluble APPalpha $(\mathrm{SAPP} \alpha)$ through translational repression and immunodepletion, respectively. APP has normal physiological functions related to synapse formation so it would be advantageous to reduce $A \beta$ while maintaining APP and $\operatorname{APP} \alpha$ levels. We observed exacerbation of FXS phenotypes in $\mathrm{Fmrl}^{\mathrm{KO}}$ mice treated with a high dose of anti-A $\beta$ or genetically null for APP (Fmr1 ${ }^{K O} / A p p^{K O}$ mice) suggesting that over-reduction of APP or a catabolite (presumably $\mathrm{A} \beta$ ) is as toxic as over-expression likely due to the loss of neuroprotective $\operatorname{sAPP} \alpha$. $\alpha$ - and $\gamma$-secretases are additional drug targets for reducing $A \beta$ levels. Activation of $\alpha$-secretases, which cleave within the $\mathrm{A} \beta$ transmembrane region, would increase the production of the neuroprotective sAPP $\alpha$ fragment and decrease $A \beta$. The problem associated with the use of $\alpha$ - or $\gamma$-secretase drugs is that they modulate proteolytic processing of other proteins that are critical for cellular function (Vincent and Govitrapong, 2011; Wolfe, 2012). Thus, in our opinion inhibition of BACE- 1 is a plausible therapeutic strategy to reduce $A \beta$ and rescue ensuing phenotypes in $F m r 1^{K O}$ mice while maintaining APP and sAPP $\alpha$ levels. Unfortunately, the design of BACE-1 inhibitors has proven challenging due to the large size of the catalytic pocket of the enzyme (Gravitz, 2011). As a result, currently identified BACE-1 inhibitors are largely excluded from reaching the central nervous system. BACE-1 inhibitors currently in trials, although able to cross the brain-blood barrier (BBB), display limited brain bioavailability. Therefore, approaches that affect BACE-1 expression levels rather than catalytic activity are being actively sought.

\section{ER-BASED ACETYLTRANSFERASES REGULATE BACE-1 LEVELS AND ACTIVITY}

As part of our $\mathrm{AD}$-related research, we discovered a novel form of post-translational regulation of membrane proteins that has a dramatic impact on BACE-1 metabolism. Specifically, nascent BACE-1 is acetylated in the lumen of the endoplasmic reticulum (ER). The acetylated intermediates are able to reach the Golgi apparatus and complete maturation whereas non-acetylated intermediates are retained in the ER/Golgi intermediate compartment (ERGIC) and degraded (Costantini et al., 2007; Jonas et al., 2008; Pehar and Puglielli, 2013). We identified two novel acetyltransferases (ATases), ATase 1 and ATase2, which acetylate BACE-1 and thus regulate its levels and activity (Costantini et al., 2007; Ko and Puglielli, 2009). Both ATases are associated with ER and ERGIC membranes, have one single membrane domain, have a highly conserved catalytic domain that faces the lumen of the

Table 1 | Expected effects of drugs in clinical trials for FXS on APP, A $\beta$, and/or BACE-1.

\begin{tabular}{|c|c|c|c|}
\hline Drug (clinical trial sponsor) & Drug activity & Expected effect & Reference \\
\hline Acamprosate (Indiana University) & $\mathrm{GABA}_{(\mathrm{A} \text { and } \mathrm{B})}$ agonist & $\downarrow A \beta$ endocytosis & Erickson et al. (2010) \\
\hline AFQ056 (Novartis Pharmaceuticals) & mGluR $_{5}$ antagonist & $\downarrow A P P$ and $A \beta$ & Levenga et al. (2011) \\
\hline Donepezil (Stanford University) & $\begin{array}{l}\text { Acetylcholinesterase inhibitor, } \\
\text { GSK3 inhibitor }\end{array}$ & $\downarrow \mathrm{BACE}-1$ and $\mathrm{A} \beta$ & Noh etal. (2009), Sahu etal. (2012) \\
\hline Fenobam (Neuropharm Ltd; FRAXA) & mGluR $_{5}$ antagonist & $\downarrow A P P$ and $A \beta$ & Berry-Kravis et al. (2009), Malter etal. (2010) \\
\hline Ganaxolone (Marinus Pharmaceuticals) & Neurosteroid & $\downarrow A \beta$ & Heulens et al. (2012) \\
\hline Lithium (FRAXA) & GSK3 inhibitor & $\downarrow$ BACE-1 and $A \beta$ & $\begin{array}{l}\text { Berry-Kravis etal. (2008), Mines and Jope } \\
\text { (2011), Yu et al. (2012) }\end{array}$ \\
\hline Lovastatin (FRAXA) & Statin & $\downarrow A \beta$ and $\uparrow \mathrm{sAPP} \alpha$ & $\begin{array}{l}\text { Kojro etal. (2001), Asai etal. (2010), } \\
\text { Osterweil etal. (2013) }\end{array}$ \\
\hline Memantine (Indiana University) & NMDAR antagonist & $\downarrow A P P$ and $A \beta$ & Erickson etal. (2009), Ray etal. (2010) \\
\hline Minocycline (UC-Davis; FRAXA) & $\begin{array}{l}\text { Antibiotic (tetracycline } \\
\text { derivative) }\end{array}$ & $\begin{array}{l}\downarrow \mathrm{BACE}-1, \uparrow \mathrm{sAPP} \alpha \\
\text { and } \downarrow \mathrm{A} \beta\end{array}$ & $\begin{array}{l}\text { Paribello et al. (2010), Siopi et al. (2011), } \\
\text { Ferretti etal. (2012) }\end{array}$ \\
\hline R04917523 (Hoffmann-La Roche) & mGluR $_{5}$ antagonist & $\downarrow A P P$ and $A \beta$ & - \\
\hline Sertraline (UC-Davis) & Serotonin reuptake inhibitor & $\uparrow \mathrm{ADAM} 10$ and $\mathrm{sAPP} \alpha$ & Indah Winarni et al. (2012) \\
\hline STX107 (Seaside Therapeutics) & mGluR $_{5}$ antagonist & $\downarrow A P P$ and $A \beta$ & - \\
\hline STX209/Arbaclofen (Seaside Therapeutics) & $\mathrm{GABA}_{(\mathrm{B})}$ agonist & $\downarrow A \beta$ endocytosis & Berry-Kravis et al. (2012) \\
\hline Vitamins $\mathrm{C}$ and $\mathrm{E}\left(\mathrm{MIABHR}^{1}\right)$ & Antioxidants & $\downarrow A \beta$ & - \\
\hline
\end{tabular}

\footnotetext{
${ }^{1}$ The Mediterranean Institute for the Advance of Biotechnology and Health Research
} 
organelle (Ko and Puglielli, 2009), are expressed in neurons, and are upregulated in AD brain (Ding et al., 2012). We also identified two novel biochemical compounds, compound 9 (6-chloro-5Hbenzo[a]phenoxazin-5-one) and compound 19 (2-chloro-3-(2ethoxyanilino)-1,4-dihydronaphthalene-1,4-dione), that target ATase- 1 and ATase- 2 with high specificity and no apparent offsite effects (Ding et al., 2012). In cellular (Ding et al., 2012) and animal models of $\mathrm{AD}$, these compounds dramatically reduce $\mathrm{A} \beta$. Importantly, preliminary studies show that pharmacologic inhibition of ATase 1 and ATase 2 rescues synaptic deficits and extends the lifespan of APP overexpressing mice without evident toxicity. ATase 1 and ATase2 display important structural differences from other classes of ATases (Pehar and Puglielli, 2013), which could explain why widespread off-site effects were not observed when ATase inhibitors were administered to cellular systems (Ding et al., 2012). Importantly, a single-nucleotide polymorphism that inactivates ATase 1 has been identified in $<2 \%$ of the general population. Since no disease association has been reported, we speculate that ATases are viable targets for therapeutic intervention. Thus, the identification of ATase 1 and ATase 2 has opened a new field of research and sparked interest in manipulating this pathway for therapeutic benefits in $\mathrm{AD}$. While our results were obtained in AD-relevant settings, we propose to extend these findings to FXS.

\section{BACE-1: A BENCH-TO-BEDSIDE TRANSLATION PLAN FOR FXS}

The prospect that FXS phenotypes can be reduced by targeting APP processing is stimulating and deserves close attention. The central hypothesis driving our translation plan is that biochemical inhibition of BACE-1 activity will rescue critical aspects of FXS pathology by reducing amyloidogenic processing of APP. We propose a three-step plan for validating the pathophysiology of APP, $A \beta$, and BACE-1 in FXS and the efficacy of the ATase inhibitors in attenuating disease phenotypes. Our ultimate goal is to generate the necessary preclinical data for a BACE-1 inhibitor trial in FXS. Inhibition of BACE-1 with ATase inhibitors potentially offers several advantages in the treatment of amyloidogenic disorders including substrate specificity and $\mathrm{BBB}$ penetrance.

In Step 1, we propose to assess BACE-1 knockdown in $F m r 1^{K O}$ mice on established FXS phenotypes. The creation of tetracycline-inducible $\mathrm{Cre} / \mathrm{Fmr1} \mathrm{I}^{\mathrm{KO}} / \mathrm{iBACE^{HET }}$ mice would allow for genetic knockdown of BACE-1 at varied points in development (gestational, postnatal, and adult) prior to assessing rescue of phenotypes (seizures, electrophysiology, behavior, sleep, dendritic spine, and biomarker expression). The timing of BACE-1 knockdown with Cre technology could provide valuable data regarding the optimal subject age for therapeutic treatments. Chronic pharmacological inhibition of $\mathrm{mGluR}_{5}$ reversed established FXS phenotypes in adult $F m r 1^{K O}$ mice (Michalon et al., 2012), and a single dose, open-label clinical trial of the $\mathrm{mGluR}_{5}$ antagonist fenobam improved prepulse inhibition in adult FXS patients (Berry-Kravis et al., 2009); however, earlier intervention may show improved efficacy. Results with the $F m r 1^{K O} / B A C E-1^{H E T}$ mice could then be used as an efficacy standard for pharmacological BACE-1 interventions. Of note, BACE-1 knockdown in $F m r 1^{K O}$ mice is expected to reduce $\mathrm{A} \beta$ and rescue hyperexcitability and seizures; however, these phenotypes are exacerbated in BACE$1^{K O}$ mice (Hu et al., 2010). Thus, we propose to reduce, not obliterate, BACE- 1 activity as some $A \beta$ is required for synaptic homeostasis.

In Step 2, we propose to study the pathophysiology of APP and $\mathrm{A} \beta$ in $d f m r$ flies. Drosophila melanogaster contain both the $d f m r$ and APPL genes, which are closely related to the mammalian FMR1 and APP genes, and share many of the same diseaserelated phenotypes. Flies are a less expensive, well-established FXS model (Bushey et al., 2011; McBride et al., 2012; Tessier and Broadie, 2012) and genetic crosses have the potential to elucidate the roles of APP and A $\beta$ in learning, memory, sleep/wake cycles, and biomarker expression.

In Step 3, we propose to inhibit ATasel with compound 9 in FXS mouse, fly, and human models. Compound 9 efficacy can be compared with BACE-1 knockdown mice, other BACE1 inhibitors, and anti-A $\beta$ therapies. In addition, the effect of compound 9 on APP processing can be assessed in peripheral blood mononuclear cells (PBMC) isolated from FXS patients. Preliminary studies from our laboratory indicate that $A \beta$ is a potential blood-based biomarker for FXS (Westmark et al., 2011 a,b); thus, it is important to understand the effects of BACE-1 inhibitors on both brain and systemic A $\beta$ levels in FXS. Overall, these complementary but distinct approaches to study the biology of APP, A $\beta$, and BACE-1 in FXS and to rescue disease phenotypes in response to compound 9 could provide solid preclinical data to support testing BACE-1 inhibitors in FXS clinical trials.

\section{CONCLUDING REMARKS}

Due to the inordinate cost of bringing a drug to market, it is highly unlikely that disease-specific drug screens can be performed for more than a couple dozen genetic diseases, leaving the vast majority out of the pharmacological lottery. For these patients and their families, the best hope is repurposing drugs developed for other diseases. Even for single gene diseases with clear etiologies such as FXS, it is unlikely that a single intervention will overcome most of the molecular defects. For example, pharmacological interventions of the well-studied mGluR $_{5}$ pathway in FXS have been successful in overcoming certain (learning deficits and propensity toward audiogenic seizures), but not other (circadian and sleep problems), aspects of the disease in fly and rodent models. This initial research already suggests that "cocktails" of pharmacological treatments will be needed to treat the likely multiple pathways that are affected. From these two perspectives, a cogent case can be made that the identification of "common molecular targets" in different diseases is both economically and scientifically sound. We have identified APP and A $\beta$ as common molecular targets in $\mathrm{AD}$ and FXS and we hypothesize that BACE-1 inhibitors, as developed for the treatment of AD, will benefit FXS patients. Herein, we have provided a framework for how APP and A $\beta$ could disturb synaptic homeostasis as well as future directions for generating the necessary preclinical data to justify a pilot clinical trial with a BACE-1 inhibitor in FXS.

\section{ACKNOWLEDGMENT}

This work was supported by FRAXA Research Foundation. 


\section{REFERENCES}

Asai, M., Iwata, N., Tomita, T., Iwatsubo, T., Ishiura, S., Saido, T. C., et al. (2010). Efficient four-drug cocktail therapy targeting amyloid-beta peptide for Alzheimer's disease. J. Neurosci. Res. 88, 3588-3597.

Auerbach, B. D., Osterweil, E. K., and Bear, M. F. (2011). Mutations causing syndromic autism define an axis of synaptic pathophysiology. Nature 480, 63-68.

Bassell, G. J., and Warren, S. T. (2008). Fragile X syndrome: loss of local mRNA regulation alters synaptic development and function. $\mathrm{Neu}$ ron $60,201-214$

Bear, M. F., Huber, K. M., and Warren, S. T. (2004). The mGluR theory of fragile X mental retardation. Trends Neurosci. 27, 370-377.

Beckel-Mitchener, A., and Greenough, W. T. (2004). Correlates across the structural, functional, and molecular phenotypes of fragile X syndrome. Ment. Retard. Dev. Disabil. Res. Rev. 10, 53-59.

Berry-Kravis, E., Hessl, D., Coffey, S., Hervey, C., Schneider, A., Yuhas, J. et al. (2009). A pilot open label, single dose trial of fenobam in adults with fragile X syndrome. J. Med. Genet. 46, 266-271.

Berry-Kravis, E., Knox, A., and Hervey, C. (2011). Targeted treatments for fragile X syndrome. J. Neurodev. Disord. 3, 193-210.

Berry-Kravis, E., Sumis, A., Hervey, C. Nelson, M., Porges, S. W., Weng, N., et al. (2008). Open-label treatment trial of lithium to target the underlying defect in fragile X syndrome. $J$. Dev. Behav. Pediatr. 29, 293-302.

Berry-Kravis, E. M., Hessl, D., Rathmell, B., Zarevics, P., Cherubini, M., Walton-Bowen, K., et al. (2012) Effects of STX209 (arbaclofen) on neurobehavioral function in children and adults with fragile $\mathrm{X}$ syndrome: a randomized, controlled, phase 2 trial. Sci. Transl. Med. 4, 152ra127.

Bhakar, A. L., Dolen, G., and Bear, M. F. (2012). The pathophysiology of fragile $\mathrm{X}$ (and what it teaches us about synapses). Annu. Rev. Neurosci. 35, 417-443.

Bushey, D., Tononi, G., and Cirelli, C. (2011). Sleep and synaptic homeostasis: structural evidence in Drosophila. Science 332, 1576-1581.

Caccamo, A., Maldonado, M. A., Majumder, S., Medina, D. X., Holbein, W., Magri, A., et al. (2011). Naturally secreted amyloidbeta increases mammalian target of rapamycin (mTOR) activity via a PRAS40-mediated mechanism. I. Biol. Chem. 286, 8924-8932.
Cao, Q., Huang, Y. S., Kan, M. C. and Richter, J. D. (2005). Amyloid precursor proteins anchor CPEB to membranes and promote polyadenylation-induced translation. Mol. Cell. Biol. 25 10930-10939.

Casley, C. S., Lakics, V., Lee, H. G. Broad, L. M., Day, T. A., Cluett, T., et al. (2009). Up-regulation of astrocyte metabotropic glutamate receptor 5 by amyloid-beta peptide. Brain Res. 1260, 65-75.

Chang, W. P., Huang, X., Downs, D. Cirrito, J. R., Koelsch, G., Holtzman, D. M., etal. (2011). Betasecretase inhibitor GRL-8234 rescues age-related cognitive decline in APP transgenic mice. FASEB J. 25, 775784

Chasseigneaux, S., Dinc, L., Rose C., Chabret, C., Coulpier, F., Topilko, P., etal. (2011). Secreted amyloid precursor protein beta and secreted amyloid precursor protein alpha induce axon outgrowth in vitro through Egrl signaling pathway. PLoS ONE 6:e16301. doi: 10.1371/journal.pone.0016301

Chen, S., Wang, J. M., Irwin, R W., Yao, J., Liu, L., and Brinton, R. D. (2011). Allopregnanolone promotes regeneration and reduces beta-amyloid burden in a preclinical model of Alzheimer's disease. PLoS ONE 6:e24293. doi: 10.1371/journal.pone.0024293

Claasen, A. M., Guevremont, D., Mason-Parker, S. E., Bourne, K., Tate, W. P., Abraham, W. C., et al. (2009). Secreted amyloid precursor protein-alpha upregulates synaptic protein synthesis by a protein kinase G-dependent mechanism. Neurosci. Lett. 460, 92-96.

Cochet, M., Donneger, R., Cassier, E., Gaven, F., Lichtenthaler, S. F., Marin, P., et al. (2013). 5-HT(4) receptors constitutively promote the non-amyloidogenic pathway of APP cleavage and interact with ADAM10. ACS Chem. Neurosci. 4, 130-140.

Costantini, C., Ko, M. H., Jonas, M. C., and Puglielli, L. (2007). A reversible form of lysine acetylation in the ER and Golgi lumen controls the molecular stabilization of BACE1. Biochem. J. 407, 383-395.

Cruz-Martin, A., Crespo, M., and Portera-Cailliau, C. (2010). Delayed stabilization of dendritic spines in fragile X mice. J. Neurosci. 30, 77937803.

Danysz, W., and Parsons, C. G. (2012). Alzheimer's disease, betaamyloid, glutamate, NMDA receptors and memantine-searching for the connections. Br. J. Pharmacol 167, 324-352.

de Vrij, F. M., Levenga, J., van der Linde, H. C., Koekkoek, S. K., De Zeeuw, C. I., Nelson, D. L., et al. (2008). Rescue of behavioral phenotype and neuronal protrusion morphology in Fmr1 KO mice. Neurobiol. Dis. 31, 127-132.

Ding, Y., Ko, M. H., Pehar, M., Kotch, F., Peters, N. R., Luo, Y., et al. (2012). Biochemical inhibition of the acetyltransferases ATase 1 and ATase2 reduces beta-secretase (BACE1) levels and $\mathrm{A} \beta$ generation. J. Biol. Chem. 287, 8424-8433.

Dolen, G., Osterweil, E., Rao, B. S., Smith, G. B., Auerbach, B. D., Chattarji, S., et al. (2007). Correction of fragile X syndrome in mice. Neuron 56, 955-962.

Erickson, C. A., Mullett, J. E., and McDougle, C. J. (2009). Open-label memantine in fragile X syndrome. $J$. Autism Dev. Disord. 39, 1629-1635.

Erickson, C. A., Mullett, J. E., and McDougle, C. J. (2010). Brief report: acamprosate in fragile $\mathrm{X}$ syndrome. J. Autism. Dev. Disord. 40, 1412-1416.

Ferreira, S. T., and Klein, W. L. (2011). The $A \beta$ oligomer hypothesis for synapse failure and memory loss in Alzheimer's disease. Neurobiol. Learn. Mem. 96, 529-543.

Ferretti, M. T., Allard, S., Partridge, V., Ducatenzeiler, A., and Cuello, A. C. (2012). Minocycline corrects early, pre-plaque neuroinflammation and inhibits BACE-1 in a transgenic model of Alzheimer's diseaselike amyloid pathology. J. Neuroinflammation. 9:62. doi: 10.1186/17422094-9-62

Ghosh, A. K., Brindisi, M., and Tang, J. (2012). Developing betasecretase inhibitors for treatment of Alzheimer's disease. J. Neurochem. 120(Suppl. 1), 71-83.

Ghosh, A. K., Kumaragurubaran, N., Hong, L., Kulkarni, S., Xu, X., Miller, H. B., et al. (2008). Potent memapsin 2 (beta-secretase) inhibitors: design, synthesis, protein-ligand X-ray structure, and in vivo evaluation. Bioorg. Med. Chem. Lett. 18, 1031-1036.

Goebel-Goody, S. M., Wilson-Wallis, E. D., Royston, S., Tagliatela, S. M., Naegele, J. R., and Lombroso, P. J. (2012). Genetic manipulation of STEP reverses behavioral abnormalities in a fragile $\mathrm{X}$ syndrome mouse model. Genes Brain Behav. 11, 586600

Gralle, M., Botelho, M. G., and Wouters, F. S. (2009). Neuroprotective secreted amyloid precursor protein acts by disrupting amyloid precursor protein dimers. J. Biol. Chem. 284, 1501615025.

Gravitz, L. (2011). Drugs: a tangled web of targets. Nature 475, S9-S11.

Gross, C., Berry-Kravis, E. M., and Bassell, G. J. (2012). Therapeutic strategies in fragile $\mathrm{X}$ syndrome: dysregulated mGluR signaling and beyond. Neuropsychopharmacology 37, 178195.

Hagerman, R. J., Berry-Kravis, E., Kaufmann, W. E., Ono, M. Y., Tartaglia, N., Lachiewicz, A., etal. (2009). Advances in the treatment of fragile X syndrome. Pediatrics 123, 378-390. Heo, J. H., Lee, H., and Lee, K. M. (2013). The possible role of antioxidant vitamin C in Alzheimer's disease treatment and prevention. Am. J. Alzheimers Dis. Other Demen. 28, 120-125.

Heulens, I., D’Hulst, C., Van Dam, D., De Deyn, P. P., and Kooy, R. F. (2012). Pharmacological treatment of fragile $\mathrm{X}$ syndrome with GABAergic drugs in a knockout mouse model. Behav. Brain Res. 229, 244-249.

Hoe, H. S., Lee, H. K., and Pak, D. T. (2012). The upside of APP at synapses. CNS Neurosci. Ther. 18, 47-56.

Hsieh, H., Boehm, J., Sato, C., Iwatsubo, T., Tomita, T., Sisodia, S., et al. (2006). AMPAR removal underlies Abeta-induced synaptic depression and dendritic spine loss. Neuron 52, 831-843.

Hu, X., Zhou, X., He, W., Yang, J., Xiong, W., Wong, P., et al. (2010). BACE1 deficiency causes altered neuronal activity and neurodegeneration. J. Neurosci. 30, 8819-8829.

Huber, K. M., Gallagher, S. M., Warren, S. T., and Bear, M. F. (2002). Altered synaptic plasticity in a mouse model of fragile $\mathrm{X}$ mental retardation. Proc. Natl. Acad. Sci. U.S.A. 99, 7746-7750.

Indah Winarni, T., Chonchaiya, W., Adams, E., Au, J., Mu, Y., Rivera, S. M., et al. (2012). Sertraline may improve language developmental trajectory in young children with fragile $\mathrm{x}$ syndrome: a retrospective chart review. Autism Res. Treat. 2012, 104317.

Ishida, A., Furukawa, K., Keller, J. N., and Mattson, M. P. (1997). Secreted form of beta-amyloid precursor protein shifts the frequency dependency for induction of LTD, and enhances LTP in hippocampal slices. Neuroreport 8, 2133-2137.

Jonas, M. C., Costantini, C., and Puglielli, L. (2008). PCSK9 is required for the disposal of nonacetylated intermediates of the nascent membrane protein BACE1. EMBO Rep. 9, 916-922. 
Kamenetz, F., Tomita, T., Hsieh, H., Seabrook, G., Borchelt, D., Iwatsubo, T., et al. (2003). APP processing and synaptic function. Neuron 37, 925-937.

Kang, J. E., Lim, M. M., Bateman, R. J., Lee, J. J., Smyth, L. P., Cirrito, J. R., et al. (2009). Amyloid-beta dynamics are regulated by orexin and the sleep-wake cycle. Science 326, 1005-1007.

Kelleher, R. J. III, and Bear, M. F. (2008). The autistic neuron: troubled translation? Cell 135, 401-406.

Kelley, D. J., Davidson, R. J., Elliott, J. L., Lahvis, G. P., Yin, J. C., and Bhattacharyya, A. (2007). The cyclic AMP cascade is altered in the fragile $\mathrm{X}$ nervous system. PLoS ONE 2:e931. doi: 10.1371/journal.pone.0000931

Ko, M. H., and Puglielli, L. (2009). Two endoplasmic reticulum (ER)/ER Golgi intermediate compartmentbased lysine acetyltransferases posttranslationally regulate BACE1 levels. J. Biol. Chem. 284, 2482-2492.

Koffie, R. M., Hyman, B. T., and SpiresJones, T. L. (2011). Alzheimer's disease: synapses gone cold. Mol. Neurodegener. 6, 63.

Kojro, E., Gimpl, G., Lammich, S., Marz, W., and Fahrenholz, F. (2001). Low cholesterol stimulates the nonamyloidogenic pathway by its effect on the alpha-secretase ADAM 10. Proc. Natl. Acad. Sci. U.S.A. 98, 5815-5820.

Lacor, P. N., Buniel, M. C., Chang, L., Fernandez, S. J., Gong, Y., Viola, K. L., et al. (2004). Synaptic targeting by Alzheimer's-related amyloid beta oligomers. J. Neurosci. 24, 1019110200.

Lee, E. K., Kim, H. H., Kuwano, Y., Abdelmohsen, K., Srikantan, S., Subaran, S. S., et al. (2010). hnRNP C promotes APP translation by competing with FMRP for APP mRNA recruitment to P bodies. Nat. Struct. Mol. Biol. 17, 732-739.

Levenga, J., Hayashi, S., de Vrij, F. M., Koekkoek, S. K., van der Linde, H. C., Nieuwenhuizen, I., et al. (2011). AFQ056, a new mGluR5 antagonist for treatment of fragile $\mathrm{X}$ syndrome. Neurobiol. Dis. 42, 311-317.

Liao, L., Park, S. K., Xu, T., Vanderklish, P., and Yates, J. R. III. (2008). Quantitative proteomic analysis of primary neurons reveals diverse changes in synaptic protein content in fmrl knockout mice. Proc. Natl. Acad. Sci. U.S.A. 105, 15281-15286.

Luscher, C., and Huber, K. M. (2010). Group 1 mGluR-dependent synaptic long-term depression: mechanisms and implications for circuitry and disease. Neuron 65, 445-459.
Ma, T., Hoeffer, C. A., CapetilloZarate, E., Yu, F., Wong, H., Lin, M. T., et al. (2010). Dysregulation of the mTOR pathway mediates impairment of synaptic plasticity in a mouse model of Alzheimer's disease. PLoS ONE 5:e12845. doi: 10.1371/journal.pone.0012845

Ma, T., and Klann, E. (2012). Amyloid beta: linking synaptic plasticity failure to memory disruption in Alzheimer's disease. J. Neurochem. 120(Suppl. 1), 140-148.

Malter, J. S., Ray, B. C., Westmark, P. R., and Westmark, C. J. (2010). Fragile X syndrome and Alzheimer's disease: another story about APP and beta-amyloid. Curr. Alzheimer Res. 7, 200-206.

McBride, S. M., Bell, A. J., and Jongens, T. A. (2012). Behavior in a drosophila model of fragile X. Results Probl. Cell Differ. 54, 83-117.

McBride, S. M., Choi, C. H., Wang, Y., Liebelt, D., Braunstein, E., Ferreiro, D., et al. (2005). Pharmacological rescue of synaptic plasticity, courtship behavior, and mushroom body defects in a drosophila model of fragile X syndrome. Neuron 45 753-764.

Michalon, A., Sidorov, M., Ballard T. M., Ozmen, L., Spooren, W. Wettstein, J. G., et al. (2012). Chronic pharmacological mGlu5 inhibition corrects fragile $\mathrm{X}$ in adult mice. $\mathrm{Neu}$ ron $74,49-56$.

Mines, M. A., and Jope, R. S. (2011). Glycogen synthase kinase-3: a promising therapeutic target for fragile x syndrome. Front. Mol. Neurosci. 4:35. doi: 10.3389/fnmol.2011.00035

Morgan, D. (2011). Immunotherapy for Alzheimer's disease. J. Intern. Med. 269, 54-63.

Nalbantoglu, J., Tirado-Santiago, G. Lahsaini, A., Poirier, J., Goncalves, O., Verge, G., et al. (1997). Impaired learning and LTP in mice expressing the carboxy terminus of the Alzheimer amyloid precursor protein. Nature 387, 500-505.

Noh, M. Y., Koh, S. H., Kim, Y., Kim, H. Y., Cho, G. W., and Kim, S. H. (2009). Neuroprotective effects of donepezil through inhibition of GSK-3 activity in amyloid-beta-induced neuronal cell death. J. Neurochem. 108, 1116-1125.

Osterweil, E. K., Chuang, S. C. Chubykin, A. A., Sidorov, M. Bianchi, R., Wong, R. K., et al. (2013). Lovastatin corrects excess protein synthesis and prevents epileptogenesis in a mouse model of fragile X syndrome. Neuron 77, 243-250.

Palop, J. J., Chin, J., Roberson, E. D. Wang, J., Thwin, M. T., Bien-Ly,
N., et al. (2007). Aberrant excitatory neuronal activity and compensatory remodeling of inhibitory hippocampal circuits in mouse models of Alzheimer's disease. Neuron 55, 697-711.

Paribello, C., Tao, L., Folino, A., BerryKravis, E., Tranfaglia, M., Ethell, I. M., et al. (2010). Open-label addon treatment trial of minocycline in fragile X syndrome. BMC Neurol. 10:91. doi: 10.1186/1471-2377-10-91

Parodi, J., Sepulveda, F. J., Roa, J., Opazo, C., Inestrosa, N. C., and Aguayo, L. G. (2010). Beta-amyloid causes depletion of synaptic vesicles leading to neurotransmission failure. J. Biol. Chem. 285, 2506-2514.

Pehar, M., and Puglielli, L. (2013). Lysine acetylation in the lumen of the ER: a novel and essential function under the control of the UPR. Biochim. Biophys. Acta 1833, 686697.

Ray, B., Banerjee, P. K., Greig, N. H., and Lahiri, D. K. (2010). Memantine treatment decreases levels of secreted Alzheimer's amyloid precursor protein (APP) and amyloid beta (A $\beta$ ) peptide in the human neuroblastoma cells. Neurosci. Lett. 470, 1-5.

Renner, M., Lacor, P. N., Velasco, P. T., Xu, J., Contractor, A., Klein, W. L., et al. (2010). Deleterious effects of amyloid beta oligomers acting as an extracellular scaffold for mGluR5. Neuron 66, 739-754.

Roselli, F., Hutzler, P., Wegerich, Y., Livrea, P., and Almeida, O. F. (2009) Disassembly of shank and homer synaptic clusters is driven by soluble beta-amyloid(1-40) through divergent NMDAR-dependent signalling pathways. PLoS ONE 4:e6011. doi: 10.1371/journal.pone.0006011

Ryan, K. A., and Pimplikar, S. W. (2005) Activation of GSK-3 and phosphorylation of CRMP2 in transgenic mice expressing APP intracellular domain. J. Cell Biol. 171, 327-335.

Sahu, J. K., Gulati, S., Sapra, S., Arya, R., Chauhan, S., Chowdhury, M. R. et al. (2012). Effectiveness and safety of donepezil in boys with fragile $\mathrm{X}$ syndrome: a double-blind, randomized, controlled pilot study. J. Child Neurol. 28, 570-575.

Siopi, E., Cho, A. H., Homsi, S. Croci, N., Plotkine, M., MarchandLeroux, C., et al. (2011). Minocycline restores $\mathrm{SAPP} \alpha$ levels and reduces the late histopathological consequences of traumatic brain injury in mice. $J$. Neurotrauma 28, 2135-2143.

Sun, X., Meng, X., Zhang, J., Li, Y., Wang, L., Qin, X., et al. (2012) GABA attenuates amyloid toxicity by downregulating its endocytosis and improves cognitive impairment. J. Alzheimers Dis. 31, 635-649.

Takashima, A., Noguchi, K., Michel, G., Mercken, M., Hoshi, M., Ishiguro, K., etal. (1996). Exposure of rat hippocampal neurons to amyloid beta peptide (25-35) induces the inactivation of phosphatidyl inositol3 kinase and the activation of tau protein kinase I/glycogen synthase kinase-3 beta. Neurosci. Lett. 203, 33-36.

Taylor, C. J., Ireland, D. R., Ballagh, I., Bourne, K., Marechal, N. M., Turner, P. R., et al. (2008). Endogenous secreted amyloid precursor proteinalpha regulates hippocampal NMDA receptor function, long-term potentiation and spatial memory. Neurobiol. Dis. 31, 250-260.

Tessier, C. R., and Broadie, K. (2012). Molecular and genetic analysis of the drosophila model of fragile $\mathrm{X}$ syndrome. Results Probl. Cell Differ. 54, 119-156.

Tucker, B., Richards, R. I., and Lardelli, M. (2006). Contribution of mGluR and Fmrl functional pathways to neurite morphogenesis, craniofacial development and fragile X syndrome. Hum. Mol. Genet. 15, 3446-3458.

Vincent, B., and Govitrapong, P. (2011). Activation of the alpha-secretase processing of AbetaPP as a therapeutic approach in Alzheimer's disease. J. Alzheimers. Dis. 24(Suppl. 2), 75-94.

Wang, L. W., Berry-Kravis, E., and Hagerman, R. J. (2010). Fragile X: leading the way for targeted treatments in autism. Neurotherapeutics 7 , 264-274.

Westmark, C. J. (2013). What's happening at synapses? The role of amyloid beta-protein precursor and betaamyloid in neurological disorders. Mol. Psychiatry 18, 425-434.

Westmark, C. J., Hervey, C. M., BerryKravis, E. M., and Malter, J. S. (2011a). Effect of anticoagulants on amyloid beta-protein precursor and amyloid beta levels in plasma. J. Alzheimers Dis. Parkinsonism 1, 1-3.

Westmark, C. J., Westmark, P. R., O’Riordan, K. J., Ray, B. C., Hervey, C. M., Salamat, M. S., etal. (2011b). Reversal of fragile $\mathrm{X}$ phenotypes by manipulation of AbetaPP/Abeta levels in Fmr1 mice. PLOS ONE 6:e26549. doi: 10.1371/journal.pone.0026549

Westmark, C. J., and Malter, J. S. (2007). FMRP mediates mGluR5dependent translation of amyloid precursor protein. PLoS Biol. 5:e52. doi: 10.1371/journal.pbio.0050052

Westmark, C. J., Westmark, P. R., and Malter, J. S. (2010). 
Alzheimer's disease and Down syndrome rodent models exhibit audiogenic seizures. J. Alzheimers Dis. 20, 1009-1013.

Westmark, C. J., Westmark, P. R., and Malter, J. S. (2013). Soy-based diet exacerbates seizures in mouse models of neurological disease. J. Alzheimers Dis. 33, 797-805.

Wolfe, M. S. (2012). Gamma-secretase as a target for Alzheimer's disease. Adv. Pharmacol. 64, 127-153.

Yan, Q. J., Rammal, M., Tranfaglia, M., and Bauchwitz, R. P. (2005). Suppression of two major fragile $\mathrm{X}$ syndrome mouse model phenotypes by the mGluR5 antagonist MPEP. Neuropharmacology 49, 1053-1066.

Young, K. F., Pasternak, S. H., and Rylett, R. J. (2009). Oligomeric aggregates of amyloid beta peptide 1-42 activate ERK/MAPK in SH-SY5Y cells via the alpha7 nicotinic receptor. Neurochem. Int. 55, 796-801.

Yu, F., Zhang, Y., and Chuang, D. M. (2012). Lithium reduces BACE1 overexpression, beta amyloid accumulation, and spatial learning deficits in mice with traumatic brain injury. J. Neurotrauma 29, 2342-2351.
Zheng, H., and Koo, E. H. (2011). Biology and pathophysiology of the amyloid precursor protein. Mol. Neurodegener. 6, 27.

Conflict of Interest Statement: The authors declare that the research was conducted in the absence of any commercial or financial relationships that could be construed as a potential conflict of interest.

Received: 07 March 2013; accepted: 07 May 2013; published online: 28 May 2013.
Citation: Westmark CJ, Berry-Kravis EM, Ikonomidou C, Yin JCP and Puglielli L (2013) Developing BACE-1 inhibitors for FXS. Front. Cell. Neurosci. 7:77. doi: 10.3389/fncel.2013.00077

Copyright (C) 2013 Westmark, BerryKravis, Ikonomidou, Yin and Puglielli. This is an open-access article distributed under the terms of the Creative Commons Attribution License, which permits use, distribution and reproduction in other forums, provided the original authors and source are credited and subject to any copyright notices concerning any thirdparty graphics etc. 